\title{
Emergence of a bufonid herpesvirus in a population of the common toad (Bufo bufo) in Germany
}

\author{
Tobias Eisenberg ${ }^{1}$, Hans-Peter Hamann ${ }^{1}$, Carina Reuscher ${ }^{2}$, Axel Kwet ${ }^{3}$, Katja Klier-Heil ${ }^{4}$, \\ and Benjamin Lamp ${ }^{2}$ \\ ${ }^{1}$ Hessian State Lab LHL \\ ${ }^{2}$ Justus Liebig Universitat Giessen \\ ${ }^{3}$ German Herpetological Society (DGHT) \\ ${ }^{4}$ Nature and Biodiversity Conservation Union (NABU)
}

September 21, 2020

\begin{abstract}
Bufonid herpesvirus 1 (BfHV1) was initially described in 2018 from cases of severe dermatitis in Swiss populations of the common toad (Bufo bufo). We identified a closely related herpes virus strain in a German toad population affected by an epidemic of multifocal proliferative to ulcerative dermatitis.

Article type: Short Communication

Title: Emergence of a bufonid herpesvirus in a population of the common toad (Bufo bufo ) in Germany

Running Title: Bufonid herpesvirus in Germany

Authors:

Tobias Eisenberg ${ }^{1,2,3^{*}}$, Hans-Peter Hamann ${ }^{1}$, Carina Reuscher ${ }^{2}$, Axel Kwet $^{3}$, Katja Klier-Heil ${ }^{3,4}$, Benjamin Lamp $^{2}$

${ }^{1}$ Hessian State Laboratory (LHL), Giessen, Germany

2 Justus-Liebig-University, Giessen, Germany

${ }^{3}$ German Herpetological Society (DGHT), Fellbach, Germany

${ }^{4}$ Nature and Biodiversity Conservation Union (NABU), Ortenberg, Germany

*corresponding author, mailing address: Hessian State Laboratory (LHL), Department of Veterinary Medicine, Schubertstr. 60/ Haus 13, 35392 Giessen, Germany. Phone: 49-641-4800 5219. Fax: 49-6414800 5268. E-mail: tobias.eisenberg@lhl.hessen.de.
\end{abstract}

Keywords: bufonid herpesvirus 1, common toad, Bufo bufo, emerging disease, amphibian decline

Abstract

Bufonid herpesvirus 1 (BfHV1) was initially described in 2018 from cases of severe dermatitis in Swiss populations of the common toad (Bufo bufo ). We identified a closely related herpes virus strain in a German toad population affected by an epidemic of multifocal proliferative to ulcerative dermatitis.

Amphibians are believed to be the most endangered class of vertebrates, with an unprecedented decline of almost one third of the populations in the recent decades. At global level, the crisis has been attributed to 
environmental pollution (Slaby, Marin, Marchand, \& Lemiere, 2019), climate change (Rollins-Smith, 2017), and the spread of infectious diseases (Eisenberg et al., 2012; Gray, Miller, \& Hoverman, 2009; Martinho \& Heatley, 2012). Among the pathogens, chytridiomycosis is the best-studied example with major effects on the populations of many frogs, toads and salamanders (Fisher \& Garner, 2020; Latney \& Klaphake, 2020). The toad herpesvirus Bufonid herpesvirus 1(BfHV1), classified within the genus Batrachoviru s in the family Alloherpesviridae, has recently been described as a cause of morbidities and mortalities in toads in Switzerland, where BfHV1 was detected in skin lesions and in the central nervous system (Origgi et al., 2018). Here, we document an epidemic of severe dermatitis in a free-living population of the common toad (Bufo bufo ) in Germany starting in 2018 caused by a closely related bufonid herpesvirus strain.

The dermatitis epidemic occurred in a toad population located in central Hesse, Germany. The habitat of these toads covers a wide range of biotopes, including hardwood forests and semi-open landscapes of meadows, pastures and hedges. The central part of their habitat is a pond area of approx. $8.000 \mathrm{~m}^{2}$, which is seasonally used by many different amphibian species in order to mate and to raise their tadpoles (Table 1). The toad population has been systematically monitored in the last three years by animal conservationists, who have initiated protective measures to reduce road kills among amphibians. Migrating amphibians were collected on a $250 \mathrm{~m}$ long transect beneath the neighbouring main road almost every night in March and April using common bucket traps. The animals were collected, classified, weighed, photographed, and finally released at the designated breeding site. The availability of monitoring data of the recent years allows a rough comparison of basic measures for the population, including number, weight and health status of captured toads. In 2018, when the first cases of an unknown skin disease were observed, a number of 837 toads could be caught within the buckets. In contrast, only 245 and 431 toads were registered for 2019 and 2020, respectively. However, only a few of the captured animals showed signs of skin lesions in 2018. These animals suffered from multifocal dermatitis spots located on the dorsal and ventral side of the body (Fig. 1B, C). Affected toads usually showed multiple lesions in different manifestation stages. Typical early lesions were greyish-dark, circumscribed, round to irregularly shaped and up to $10 \mathrm{~mm}$ in diameter. In these early stages, mild proliferative superficial alterations appeared that ended up at later stages in ulcerative lesions with a crusty, cauliflower-like appearance, slightly elevated above the normal skin level (Fig. 1B). After molting of the affected skin regions of lighter areas remained, which were more yellowish pigmented (Fig. 1C). All captured toads appeared to be healthy except for the skin lesions described. Even the toads affected by severe dermatitis spots were in good nutritional condition and no neurological abnormalities were observed. No acute deaths due to the unknown dermatitis have been documented or reported from other parties for the toad population. It was therefore suspected that these skin lesions were harmless to the animals and represented skin burns possibly caused by natural tannins from the ecosystem. Due to the official protection status of toads, no biopsy was performed. No further diagnostic measures were taken as no other amphibian species in this habitat showed comparable skin lesions (Table 1).

The decision to take samples and carry out an in-depth microbiological examination was made in March 2020, when characteristic lesions were found in more than one third of all captured toads (Table 1). Skin swabs were taken from the affected toads and spontaneously molted fresh skin material was collected from two male and two female toads (permit no. 4.1.2/19.1-0183-15660/20). After extraction of the nucleic acids, all samples were examined by PCR assays for the presence of genetic material of the major amphibian pathogens Batrachochytrium $(B$.) dendrobatidis, B. salamandrivorans and ranaviruses. Furthermore, the fresh skin samples of the molted epidermis were processed and analyzed by transmission electron microscopy (TEM). While no pathogens could be detected by PCR, characteristic virus-like structures were apparent in the negatively stained TEM samples. Multiple fried egg shaped, electron dense particles could be seen. Central in these particles an icosahedral nucleocapsid with a diameter of about $120 \mathrm{~nm}$ build of capsomeres was situated. The structure was typical for members of the order Herpesvirales (Fig. 2A). Based on the nucleotide sequence of the recently described herpesvirus of toads we designed oligonucleotides to amplify a large fragment of the putative DNA polymerase gene covering most of the open reading frame (BHpf 5'-cagagcagcggtctgccgcgac3 ' and BHpr 5'-ctggcaacaccataatggctg-3'). A DNA fragment of 1,552 bp was amplified from swab samples of the affected toads (GenBank MT975973). After sub-cloning, Sanger sequencing of the plasmids, and 
phylogenetic analysis, we termed the strain BfHV1_G/H/20_1, because it showed a very close phylogenetic relationship (Fig. 2B) to the type-strain from Switzerland (BfHV1, FO1_2015, NC_040681.1). In direct comparison only four nucleic acid exchanges were found between the two herpesvirus strains in the 1,552 bp fragment, of which only one caused an amino acid exchange (A412V) after translation (YP_009552918.1).

\section{Conclusions}

A negative population trend for common toads was observed in representative long-term studies in Great Britain and Switzerland. While exact reasons for this population trend are currently unknown, an involvement of infectious diseases is very likely (Petrovan \& Schmidt, 2016). A literature search revealed that epidemic dermatitis cases in toads have already been reported in the past as "black fungus disease" (David, 2013) and that there have been previous reports from Belgium on the identification of a toad herpes virus (Garner, 2013). In addition, a virus termed Ranid herpesvirus 3 has recently been described in European common frogs as the cause behind a similar skin disease with clinically relevant lesions (Bennati, Bonetti, Lavazza, \& Gelmetti, 1994; Franklinos et al., 2018; Origgi et al., 2017). These data are suggesting that besides other microorganisms, especially chytrid fungi and ranaviruses, also herpesviruses have to be considered as an underlying agent behind a population decline among amphibians. Different consensus PCR protocols have been established as a strong diagnostic tool for the detection of all the known Ranid herpesviruses (15). The incidence of BfHV1 cases in Germany is currently unknown and data on diseased toads exist mainly from the reproductive habitat, as the shy animals are otherwise rarely noticed. In line with previous reports on the benignity of herpesvirus infections in amphibians, no toads were found or reported that died acutely of BfHV1. The skin lesions of the toads captured during this study did not significantly affect the general condition of the animals. However, the study toad population is facing a decline since the first occurrence of apparent BfHV1 disease and the proportion of BfHV1 affected animals is constantly rising since 2018 reaching over $30 \%$ in 2020. Furthermore, it seems likely that BfHV1-associated morbidities and mortalities could have been overlooked, even in this study as only healthy animals can make the strenuous journey to the site of reproduction. Dead toads are quickly disposed by scavengers in their habitat and therefore, they will rarely be noticed by humans. Even a slight loss of fitness often means that small animals fall victim to a larger predator in the wild. It remains to be determined, whether this virus is involved in the population decline documented in this study. The presence of BfHV1 disease in common toads in another region of Europe implies a greater importance of the pathogen for the European toad population. Hence, the prevalence of BfHV1 and its impact on the European toad population should be studied in more detail in future investigations.

\section{Contributors}

TE and BL conceived the study. KKH and AK found affected and control toads, respectively and submitted material. HPH conducted electron microscopy. HPH, CR and BL performed molecular experiments. TE and $\mathrm{BL}$ wrote the report and all authors approved the final manuscript.

\section{Acknowledgments}

The Hessian State Laboratory is supported by the Hessian Ministry for the Environment, Climate Change, Agriculture and Consumer Protection.

\section{Statement}

All authors do not declare any conflict of interest. No funding was received for this study.

References:

Bennati, R., Bonetti, M., Lavazza, A., \& Gelmetti, D. (1994). Skin lesions associated with herpesvirus-like particles in frogs (Rana dalmatina). Vet Rec, 135 (26), 625-626.

David, M. (2013). Schwärzepilz bei Erdkröten am Niederrhein entdeckt [in German]. Feldherpetologisches Magazin, 20 , 249. 
Eisenberg, T., Hamann, H. P., Kaim, U., Schlez, K., Seeger, H., Schauerte, N., . . . Zschöck, M. (2012). Isolation of potentially novelBrucella spp. from frogs. Appl Environ Microbiol, 78 (10), 3753-3755. doi:10.1128/AEM.07509-11

Fisher, M. C., \& Garner, T. W. J. (2020). Chytrid fungi and global amphibian declines. Nat Rev Microbiol, 18 (6), 332-343. doi:10.1038/s41579-020-0335-x

Franklinos, L. H. V., Fernandez, J. R., Hydeskov, H. B., Hopkins, K. P., Everest, D. J., Cunningham, A. A., \& Lawson, B. (2018). Herpesvirus skin disease in free-living common frogs Rana temporaria in Great Britain. Dis Aquat Organ, 129 (3), 239-244. doi:10.3354/dao03246

Garner, T. W. J. e. a. (2013). Infectious diseases that may threaten Europe's amphibians. In H. Heatwole \& J. W. Wilkinson (Eds.), Amphibian Biology (Vol. Vol. 11. Part 1, pp. 1-41): Pelagic publishing.

Gray, M. J., Miller, D. L., \& Hoverman, J. T. (2009). Ecology and pathology of amphibian ranaviruses. Dis Aquat Organ, 87 (3), 243-266. doi:10.3354/dao02138

Latney, L. V., \& Klaphake, E. (2020). Selected emerging infectious diseases of amphibians. Vet Clin North Am Exot Anim Pract, 23 (2), 397-412. doi:10.1016/j.cvex.2020.01.003

Martinho, F., \& Heatley, J. J. (2012). Amphibian mycobacteriosis. Vet Clin North Am Exot Anim Pract, 15 (1), 113-119, vii. doi:10.1016/j.cvex.2011.09.001

Origgi, F. C., Schmidt, B. R., Lohmann, P., Otten, P., Akdesir, E., Gaschen, V., . . . Stoffel, M. H. (2017). Ranid herpesvirus 3 and proliferative dermatitis in free-ranging wild common frogs (Rana temporaria). Vet Pathol, 54 (4), 686-694. doi:10.1177/0300985817705176

Origgi, F. C., Schmidt, B. R., Lohmann, P., Otten, P., Meier, R. K., Pisano, S. R. R., . . Stoffel, M. H. (2018). Bufonid herpesvirus 1 (BfHV1) associated dermatitis and mortality in free ranging common toads (Bufo bufo ) in Switzerland. Sci Rep, 8 (1), 14737. doi:10.1038/s41598-018-32841-0

Petrovan, S. O., \& Schmidt, B. R. (2016). Volunteer Conservation Action Data Reveals Large-Scale and Long-Term Negative Population Trends of a Widespread Amphibian, the Common Toad (Bufo bufo). PLoS One, 11 (10), e0161943. doi:10.1371/journal.pone.0161943

Rollins-Smith, L. A. (2017). Amphibian immunity-stress, disease, and climate change. Dev Comp Immunol, 66 , 111-119. doi:10.1016/j.dci.2016.07.002

Slaby, S., Marin, M., Marchand, G., \& Lemiere, S. (2019). Exposures to chemical contaminants: What can we learn from reproduction and development endpoints in the amphibian toxicology literature? Environ Pollut, 248 , 478-495. doi:10.1016/j.envpol.2019.02.014

Captions (2 Figures and 1 table)

Figure 1. Clinical picture of BfHV1 skin lesions in toads. A) Healthy toad skin; B) toad with prominent skin lesions on the body surface; C) appearance of proliferative and ulcerative skin changes in close-up.

Figure 2. Identification of BfHV1. A) Electron micrograph of virions from the lesions with two concentric layers indicative for a herpesvirus. B) Phylogenetic analyses of BfHV1 strain G/H/20_1 and related viruses was done by Neighbor Joining based on a 517 AA fragment of the putative DNA polymerase. Labels at end nodes indicate the species and strains of the respective herpesviruses. The protein IDs to the fragments of BfHV1 strain FO1_2015 (YP_009552918.1), BfHV1 strain G/H/20_1 (MT975973.1), ranid herpesvirus 1 strain McKinnell (RaHV1, YP_656727.1), ranid herpesvirus 2 strain ATCC VR-568 (RaHV2, YP_656618.1) are provided in parentheses. The ranid herpesvirus 3 strain FO1_2015 (RaHV3, YP_009362398.1) showed only a distant relation and served as an outgroup. The scale bar indicates substitutions per site. Bootstrapping values from 1,000 replicates are indicated.

Table 1: Captured toads of the study population as well as other amphibian species at the study location and occurrence of BfHV lesions 


\begin{tabular}{lllll}
\hline & 2018 & 2018 & 2019 & 2019 \\
\hline Amphibian species & Total no. of specimens & No. of specimens with BfHV lesions & Total no. of specimens & No. of sp \\
Bufo bufo & 837 & 2 & 245 & 10 \\
Bombina variegata & 4 & - & 2 & - \\
Pelophylax spp. & 40 & - & 45 & - \\
Rana temporaria & 32 & - & 10 & - \\
Hyla arborea & - & - & 1 & - \\
Lissotriton vulgaris & 60 & - & 55 & - \\
Ichthyosaura alpestris & 25 & - & 28 & - \\
\hline
\end{tabular}

n.d.a.: no data avialable

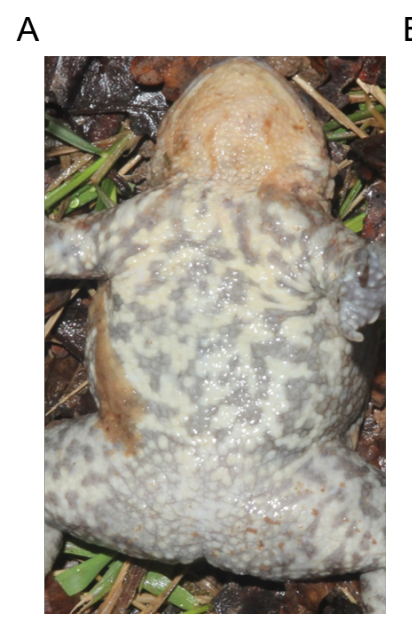

B

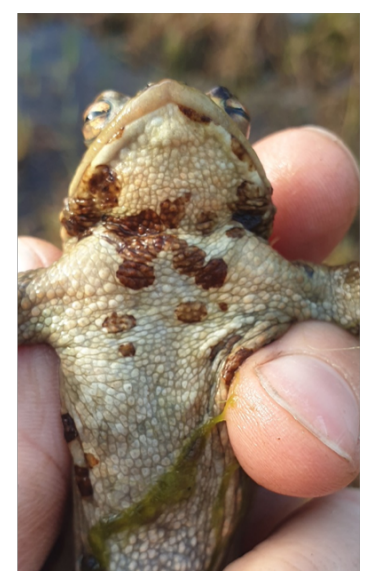

C

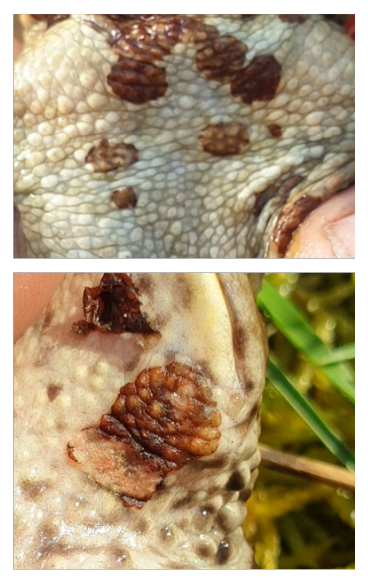


A
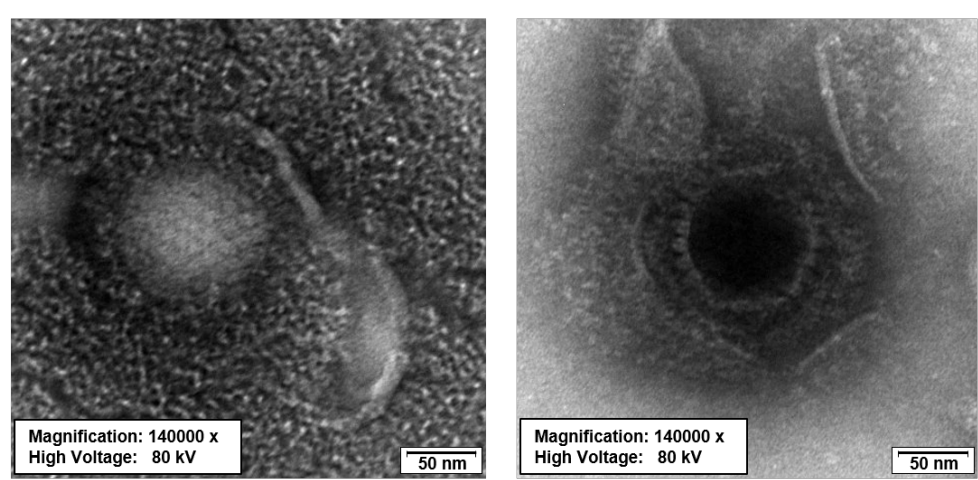

B

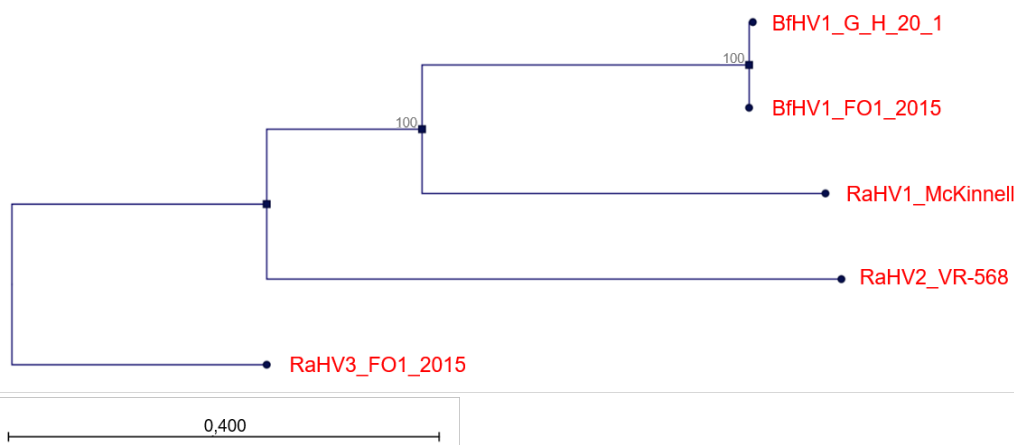

